\title{
Microbial pathogenesis in cystic fibrosis: co-ordinate regulation of heat-shock response and conversion to mucoidy in Pseudomonas aeruginosa
}

\author{
M. J. Schurr and V. Deretic* \\ Department of Microbiology and Immunology, The \\ University of Michigan Medical School, Ann Arbor, \\ Michigan, 48109-0620, USA.
}

\section{Summary}

Conversion of Pseudomonas aeruginosa to the mucoid phenotype plays a major role in the pathogenesis of respiratory infections in cystic fibrosis (CF). One mechanism responsible for mucoidy is based on mutations that inactivate the anti-o factor, MucA, which normally inhibits the alternative sigma factor, AlgU. The loss of MucA allows AlgU to freely direct transcription of the genes responsible for the production of the exopolysaccharide alginate resulting in mucoid colony morphology. In Escherichia coli, a close homologue of AlgU, $\sigma^{\mathrm{E}}$, directs transcription of several genes under conditions of extreme heat shock. Here we examined whether AlgU, besides its role in controlling alginate production, affects the heat-shock response in $\boldsymbol{P}$. aeruginosa. The $P$. aeruginosa $r p o H$ gene encoding a homologue of the major heat-shock sigma factor, $\sigma^{32}$, was found to be transcribed by AlgU containing RNA polymerase from one of its promoters $\left(P_{3}\right)$ identified in this study. Transcription of $r p o H$ from $\mathrm{P}_{3}$ was elevated upon exposure to extreme heat shock in an algU-dependent manner. Importantly, the AlgU-dependent promoter of $\mathrm{rpoH}$ was found to be activated in mucoid mucA mutants. In keeping with this observation, introduction of a wild-type mucA gene abrogated AlgU-dependent $\mathrm{rpoH}$ transcription in mucoid $P$. aeruginosa laboratory isolates and CF isolates. These results suggest that conversion to mucoidy and the heat-shock response are co-ordinately regulated in $P$. aeruginosa. The simultaneous activation of both systems in mucA mutants, selected in the lungs of CF patients, may have significance for the inflammatory processes characteristic of the establishment of chronic infection and ensuing clinical deterioration in CF.

Received 18 November, 1996; revised 10 February, 1997; accepted 12 February, 1997.*For correspondence. E-mail Deretic@umich. edu; Tel. (313) 763 1580; Fax (313) 6476243.

\section{Introduction}

Chronic respiratory infections and associated inflammation are the leading cause of high mortality and morbidity in patients with cystic fibrosis (CF) (Boat, 1989; Govan and Deretic, 1996). The overproduction of the exopolysaccharide alginate, which results in mucoid colony morphology, is a characteristic pathogenic determinant expressed by Pseudomonas aeruginosa in CF (Govan and Deretic, 1996). The muc locus, a major site of genetic alterations responsible for the conversion to the mucoid phenotype, has initially been described by Fyfe and Govan (1980). The recent molecular characterization of the genes within the muc locus at $67.5 \mathrm{~min}$ of the $P$. aeruginosa map resulted in identification of the alg $U$ mucABCD gene cluster as the major regulatory site which encodes both positive and negative factors controlling mucoidy (Boucher et al., 1996; Martin et al., 1993a; Martin et al., 1993b; Martin et al., 1993c; Schurr et al., 1994). Similar findings have been reported by others, resulting in alternative designations of algU as $\mathrm{Pa} \sigma^{\mathrm{E}}$ or algT (DeVries and Ohman, 1994; Hershberger et al., 1995; Wozniak and Ohman, 1994) and mucB as algN (Goldberg et al., 1993). The initial analysis of algU showed that its predicted gene product was homologous to the Bacillus stationary phase and sporulation sigma factor SpoOH (Martin et al., 1993a). In a subsequent study, Martin et al. (1994) showed that the -35 and -10 regions of promoters transcribed by AlgU shared considerable similarity with the known promoter consensus sequence for $\sigma^{\mathrm{E}}$, the second heat-shock sigma factor identified at the biochemical level in Escherichia coli (Erickson and Gross, 1989). These and subsequent sequence analyses permitted the identification of E. coli and Salmonella typhimurium rpoE genes based on striking homologies of their gene products with AlgU (Hiratsu et al., 1995; Martin et al., 1994; Raina et al., 1995; Rouvière et al., 1995). These observations and additional analyses have uncovered the existence of a broader family of novel alternative sigma factors termed ECF (Lonetto et al., 1994) or $\sigma^{\mathrm{E}}$-like factors (Deretic et al., 1994).

The initial experimental evidence supporting the hypothesis that alg $U$ encodes the $P$. aeruginosa equivalent of $\sigma^{\mathrm{E}}$ was presented when $E$. coli rpoE was shown to complement an algU mutation and to induce mucoidy in $P$. aeruginosa (Yu et al., 1995). Biochemical evidence that 


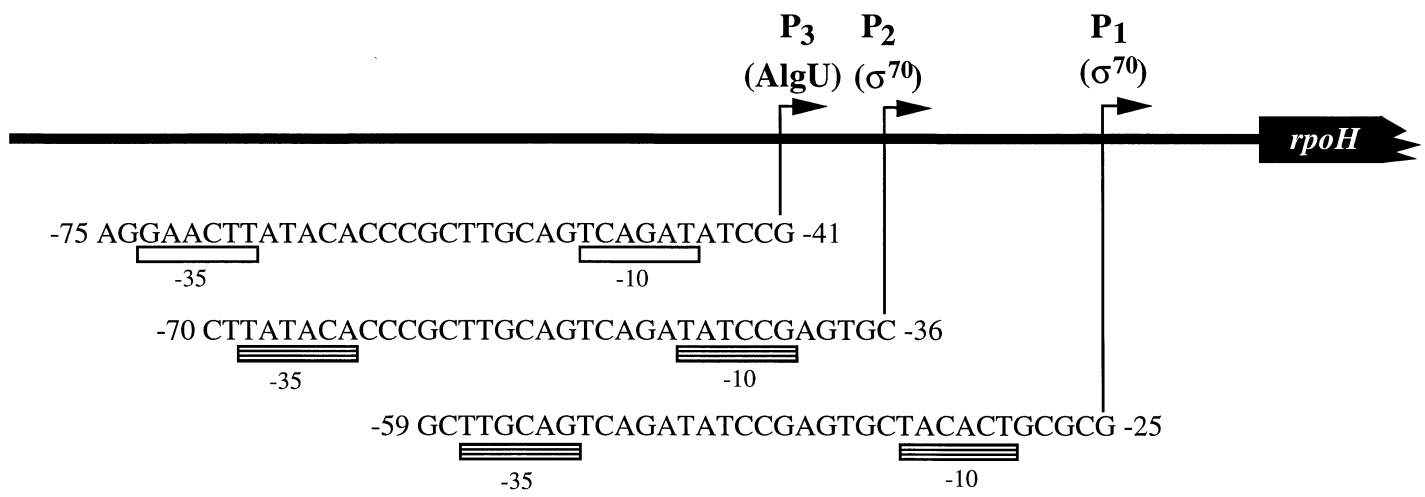

Fig. 1. The promoter region of the rpoH gene from $P$. aeruginosa. Numbering is given relative to the initiation codon of $r p o H$. Bent arrows, mapped mRNA $5^{\prime}$ ends; $\mathrm{P}_{1}$ and $\mathrm{P}_{2}, \sigma^{70}$-dependent promoters; $\mathrm{P}_{3}$, AlgU $\left(\mathrm{Pa} \sigma^{\mathrm{E}}\right)$ - dependent promoter; boxes, -35 and -10 regions of $\sigma^{70}$ (horizontal stripes) and $\sigma^{\mathrm{E}}$ (open boxes) promoters.

algU encodes a sigma factor has been reported recently (Hershberger et al., 1995; Schurr et al., 1995b). AlgU activity is controlled at a post-translational level by the products of the downstream genes (mucABCD) that encode its negative regulators. Recently, it has been demonstrated that MucA probably functions as an anti-sigma factor (Schurr et al., 1996; Xie et al., 1996). Mutations in mucA and other muc genes located in the $67.5 \mathrm{~min}$ region are responsible for the conversion to mucoidy in CF isolates and laboratory strains (Martin et al., 1993c). As a result of $m u c A$ inactivation, $\mathrm{AlgU}$ is relieved from the inhibition by its cognate anti- $\sigma$ factor and is available to direct transcription of the subordinate promoters. AlgU directs transcription of its own gene (Schurr et al., 1995a) and that of algR, a response regulator controlling critical alginate genes (Martin et al., 1994; Wozniak and Ohman, 1994). AlgU and AlgR co-operate to activate transcription of the algD gene (Martin et al., 1994; Schurr et al., 1993) encoding GDP mannose dehydrogenase (Deretic et al., 1987; Roychoudhury et al., 1989), which catalyses the first committed step in alginate synthesis. Because of this cascade of regulatory interactions, the net result of a loss of mucA is alginate overproduction and mucoid colony phenotype.

The equivalence of $E$. coli $\sigma^{\mathrm{E}}$ and $P$. aeruginosa AlgU suggests that there may be broader physiological overlaps in the function of these sigma factors (Yu et al., 1995). The sigma factor $\sigma^{32}$ that controls the heat-shock response in $E$. coli is encoded by the rpoH gene (Grossman et al., 1984). E. coli $\sigma^{32}$ controls expression of genes encoding heat-shock proteins such as GroEL, DnaJ, DnaK, and Lon (Yura et al., 1993). Interestingly, one of the E. coli rpoH promoters $\left(\mathrm{P}_{3}\right)$ is controlled by $\sigma^{\mathrm{E}}$ under conditions of extreme heat shock (Erickson and Gross, 1989; Wang and Kaguni, 1989). In order to address the question of whether AlgU, in addition to regulating mucoidy in $P$. aeruginosa, affects the heat-shock response in this organism, the promoter region of the recently characterized $P$. aeruginosa rpoH gene (Naczynski et al., 1995) and the effects of algU and mucA mutations on $\mathrm{rpoH}$ transcription were analysed. We report that AlgU is responsible for transcriptional initiation of one of the rpoH promoters (Fig. 1). We also show that mucA mutations in $P$. aeruginosa not only induce alginate production and mucoidy in this organism but also activate $\mathrm{rpoH}$ transcription, which may have downstream effects on the entire heat-shock response. As chronic inflammation is a well-recognized sequela of $P$. aeruginosa infections in $\mathrm{CF}$, it is possible that the expected increased expression in mucA mutants of highly conserved antigens such as heat-shock proteins may further complicate immune processes and contribute to the pathogenesis in CF.

\section{Results}

$S 1$ nuclease protection mapping of the $\mathrm{rpoH} m R N A$ $5^{\prime}$ ends

In order to investigate whether $r p o H$ is transcribed by AlgU $\left(\mathrm{Pa}-\sigma^{\mathrm{E}}\right)$ in $\mathrm{P}$. aeruginosa and to map the $\mathrm{rpoH}$ promoters in this organism, the region immediately upstream of the $\mathrm{rpoH}$ gene was cloned and examined by S1 nuclease protection analysis. Several bands of protection corresponding to $r p o H$ mRNA 5' ends were observed (Fig. 2). One 5' mRNA end was located $25 \mathrm{bp}$ upstream of the $\mathrm{rpoH}$ initiation codon (Figs 1 and 2). A second band of protection corresponded to the $5^{\prime}$ mRNA end at the position $41 \mathrm{bp}$ upstream of the $\mathrm{rpoH}$ translational start (Fig. 2A, lane 1). When $P$. aeruginosa was grown on minimal media, an additional 5' mRNA end was observed. This band of protection was located $36 \mathrm{bp}$ upstream of the initiation codon (Fig. 2B), was not visible in RNA extracted from cells grown in rich medium (Fig. 2A), and was more prominent when RNA was extracted from PAO6852 $\left(\right.$ algU::Tc $\left.{ }^{R}\right)$ (Fig. 2B, lanes 3 and 4). These results suggest 


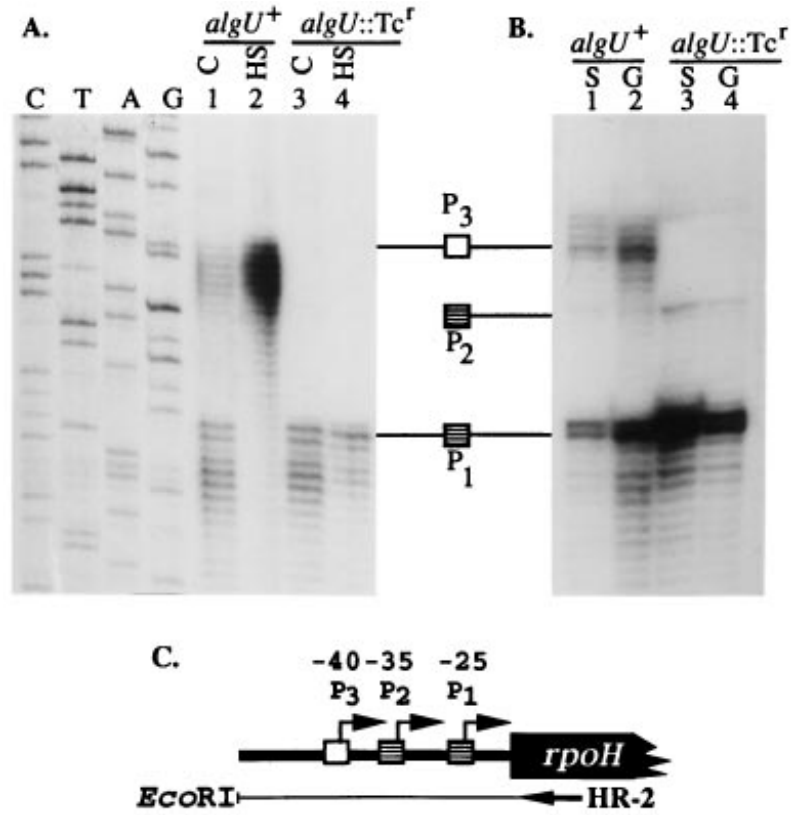

Fig. 2. Mapping of the $P$. aeruginosa $r p o H$ promoters, analysis of transcription from $\mathrm{P}_{3}$ in algU::Tc ${ }^{\mathrm{R}}$ background and induction by heat shock of the $\mathrm{P}_{3}$ promoter of $r p o \mathrm{H}$.

A. P. aeruginosa rpoH promoters mapped using RNA from cells grown in rich medium. Lanes: 1, PAO1 grown continuously at

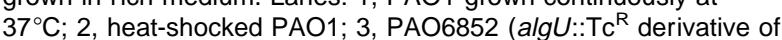
PAO1) grown at $37^{\circ} \mathrm{C} ; 4$, heat-shocked PAO6852.

B. S1 nuclease protection mapping of the $P$. aeruginosa $r p o H \mathrm{P}_{2}$ promoter using RNA from cells grown on minimal media. Lanes: 1 , PAO1 grown in minimal medium supplemented with succinate (S); 2, PAO1 grown in minimal medium supplemented with glucose $(G)$ 3, PAO6852 (algU::Tc ${ }^{\mathrm{R}}$ ) grown in minimal medium with succinate; 4, PAO6852 (algU::Tc $\left.{ }^{\mathrm{R}}\right)$ grown in minimal medium with glucose. C. Schematic representation of hybridization probe. HR-2 primer was used to generate the probe; the $E c o R I$ restriction site defines the $3^{\prime}$ end of the radiolabelled probe for $S 1$ nuclease protection analysis. Striped boxes, $\mathrm{P}_{1}$ and $\mathrm{P}_{2}$; open box, $\mathrm{P}_{3}$.

that the $P$. aeruginosa $r p o H$ gene is transcribed from at least three promoters $\left(\mathrm{P}_{1}, \mathrm{P}_{2}\right.$ and $\left.\mathrm{P}_{3}\right)$ corresponding to the mRNA start sites mapped in this study at $25 \mathrm{bp}, 36 \mathrm{bp}$, and $41 \mathrm{bp}$ upstream of the initiation codon (Fig. 1). Of the mapped mRNA $5^{\prime}$ ends, $P_{1}$ and $P_{3}$ were present under most conditions, while $P_{2}$ was detectable only on minimal media. Interestingly, the $\mathrm{P}_{2}$ signal was enhanced in algU null mutants (Fig. 2B), suggesting a possible interference of initiation from the $\mathrm{P}_{2}$ and $\mathrm{P}_{3}$ promoter or masking of the signal.

Induction of rpoH $P_{3}$ by extreme heat shock and its dependence on algU

A strong consensus $\sigma^{\mathrm{E}}$ (AlgU) promoter sequence, previously noted upstream of the $\mathrm{rpoH}$ coding sequence (Benvenisti et al., 1995; Deretic et al., 1994; Naczynski et al., 1995), was located at the canonical -35 and -10 positions in relation to the $\mathrm{P}_{3}$ band. In order to determine if $r p o H \mathrm{P}_{3}$ was AlgU-dependent, RNA from $P$. aeruginosa PAO6852 (algU::Tc ${ }^{\mathrm{R}}$ ) was subjected to $S 1$ nuclease protection analysis. The $\mathrm{P}_{3}$ band was absent in these samples (Fig. 2A, lanes 3 and 4) while it was present as expected (Martin et al., 1994; Schurr et al., 1995a) in samples with RNA from alg $U^{+}$cells (Fig. 2A, lanes 1 and 2). These results indicate that the rpoH $\mathrm{P}_{3}$ signal is dependent on the presence of a functional alg $U$ gene.

The AlgU promoters of algU $\left(\mathrm{P}_{1}\right.$ and $\left.\mathrm{P}_{3}\right)$ and $\operatorname{alg} R\left(\mathrm{R}_{\mathrm{P}}\right)$ are induced during exposure to extreme heat shock (Martin et al., 1994; Schurr et al., 1995a). In order to examine whether the $\mathrm{P}_{3}$ promoter of $\mathrm{rpoH}$ can be induced by extreme heat shock, $P$. aeruginosa PAO1 RNA was isolated from cells that were exposed to a temperature shift from $37^{\circ} \mathrm{C}$ to $50^{\circ} \mathrm{C}$. This treatment resulted in a dramatic increase in $\mathrm{rpoH} \mathrm{P}_{3}$ transcription (Fig. 2A, lane 2) as compared to cells grown at $37^{\circ} \mathrm{C}$ (Fig. $2 \mathrm{~A}$, lane 1 ). The observed activation of $\mathrm{rpoH}$ transcription from $\mathrm{P}_{3}$ under conditions of extreme heat shock (Fig. 2A, lane 2) and the absence of the corresponding transcripts in alg $U$ mutants (Fig. 2A, lanes 3 and 4) are consistent with the interpretation that $r p o H \mathrm{P}_{3}$ is an AlgU-dependent promoter.

\section{In vitro transcriptional analysis of $\mathrm{AlgU}$ and $\sigma^{70}$ promoters of $\mathrm{P}$. aeruginosa $\mathrm{rpoH}$}

Purified AlgU has been used in vitro to demonstrate its activity as a sigma factor on one of the promoters of algU $\left(P_{1}\right)$ (Schurr et al., 1995b). In order to examine whether AlgU directs transcription of the $r p o \mathrm{HP}_{3}$ promoter, purified AlgU was preincubated with core RNA polymerase and added to the standard in vitro transcriptional run-off assay (Schurr et al., 1995b) with rpoH as a template. The predicted distance from $\mathrm{P}_{3}$ initiation to the end of the truncated $\mathrm{rpoH}$ is 77 nucleotides and a transcript of this size was observed upon addition of AlgU to the mixture (Fig. 3A, lanes 2 and 3). This transcript had the expected size and was absent when the same template was incubated with RNA polymerase core alone (Fig. 3A, lane 1). These findings support the conclusion that the $r p o H \mathrm{P}_{3}$ promoter is transcribed by the AlgU ( $\mathrm{Pa} \sigma^{\mathrm{E}}$ ) RNA polymerase holoenzyme.

In a set of complementary experiments, in vitro transcription of $P_{1}$ and $P_{2}$ was investigated. Examination of the -10 (TAcAcT) and -35 (TTGcag) regions of the strong $r p o H \mathrm{P}_{1}$ promoter suggested the possibility that this promoter may be transcribed by the $\sigma^{70}$ holoenzyme. In $E$. coli, it is known that $\sigma^{70}$ directs transcription of several rpoH promoters (Erickson et al., 1987; Fujita et al., 1987; Nagai et al., 1990). In order to examine the possibility that $\sigma^{70}$ directs transcription of the $\mathrm{P}_{1}$ promoter of $P$. aeruginosa $r p o H$, in vitro transcriptional run-off analyses were performed either with core RNA polymerase reconstituted with exogenously added $\sigma^{70}$ or with $\sigma^{70}$ saturated 
A.

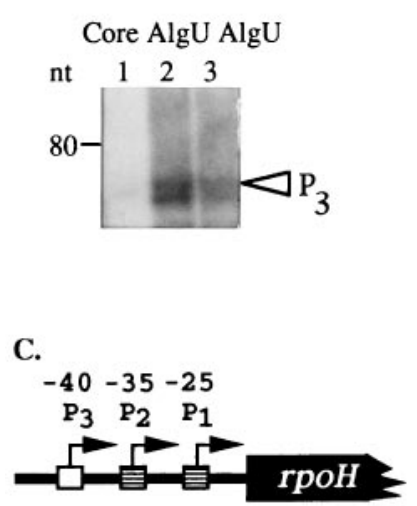

B.

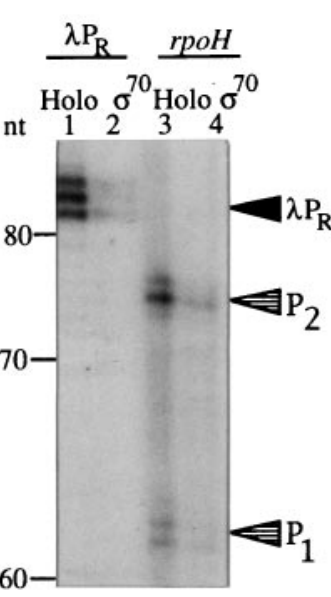

Fig. 3. AlgU directs transcription of the rpoH $\mathrm{P}_{3}$ promoter and $\sigma^{70}$ directs transcription from $r p o H \mathrm{P}_{1}$ and $\mathrm{P}_{2}$ promoters.

A. In vitro transcription from the rpoH $\mathrm{P}_{3}$ promoter. Lanes: 1 , core RNA polymerase; 2 and 3 , core RNA polymerase with AlgU. Open triangle, $r p o \mathrm{H}_{3}$ transcript.

B. $\sigma^{70}$-directed in vitro transcription from the $\lambda P_{R}$ promoter and the rpoH $\mathrm{P}_{1}$ and $\mathrm{P}_{2}$ promoters. Lanes: 1, RNA polymerase holoenzyme and the $\lambda P_{R}$ promoter; 2 , core RNA polymerase with $\sigma^{70}$ and the $\lambda P_{\mathrm{R}}$ promoter; 3, RNA polymerase holoenzyme and the rpoH promoter; 4 , core RNA polymerase with $\sigma^{70}$ and the $r p o H$ promoter. C. Schematic representation of $r p o H$ promoter positions. Open box, $r p o H$ P3 promoter; striped box, $r p o H \mathrm{P}_{1}$ and $\mathrm{P}_{2}$ promoters; filled triangle, $\lambda \mathrm{P}_{\mathrm{R}}$ transcript; striped triangles, $r p o H \mathrm{P}_{1}$ and $\mathrm{P}_{2}$ transcripts.

holoenzyme preparations. In these experiments, where the $\sigma^{70}$-dependent promoter of $\lambda P_{R}$ was used as a positive control (Fig. 3B, lanes 1 and 2), the expected size transcript corresponding to rpoH $\mathrm{P}_{1}$ was observed with the $\sigma^{70}$-containing polymerase (Fig. 3B, lanes 3 and 4 ). As expected, no transcript corresponding to $\mathrm{P}_{3}$ was observed with $\sigma^{70}$. Interestingly, a stronger second band was observed with the size corresponding to the transcript from $\mathrm{P}_{2}$, suggesting that $\sigma^{70}$ polymerase may transcribe both the $\mathrm{P}_{1}$ and $\mathrm{P}_{2}$ promoters of $r p o H$.

\section{Inactivation of mucA induces AlgU-dependent $\mathrm{rpoH}$ transcription}

As mucA has been shown to act as a negative regulator of AlgU activity (Martin et al., 1993c; Schurr et al., 1994; 1996), we tested the hypothesis that the AlgU-dependent promoter $\mathrm{P}_{3}$ of $r p o H$ may also be affected by mucA mutations. RNA from the strain PAO578I (Schurr et al., 1994) carrying the characterized mucA22 mutation (Martin et al., 1993c) was examined by S1 nuclease protection analysis. Increased transcription was observed from rpoH $\mathrm{P}_{3}$ in mucA22 cells when compared to $\mathrm{mucA}^{+}$cells (Fig. 4, lane 8 versus lane 7$)$. This effect was similar to the increased transcription of $\operatorname{alg} U \mathrm{P}_{1}$ and $\mathrm{P}_{3}$ in the same genetic background (Fig. 4, lanes 4 versus 5 for $P_{1}$; lanes 1 versus 2 for $P_{3}$ ). These observations indicate

that expression from the rpoH $\mathrm{P}_{3}$ promoter is negatively regulated by MucA and that the transcription from this promoter is elevated in mucA mutants. As another level of control, we also tested transcription of rpoH $\mathrm{P}_{3}$ in a mucB::Tc ${ }^{\mathrm{R}}$ background. MucB encodes a periplasmic protein which also negatively regulates alginate production (Martin et al., 1993b; Schurr et al., 1996). Although mucB mutations cause conversion to mucoidy, this phenotype is medium dependent and under the conditions used in the present study, the strains are normally not induced for alginate production. In keeping with the absence of increased alginate synthesis, the loss of mucB did not alter expression of rpoH $\mathrm{P}_{3}$, alg $U \mathrm{P}_{1}$ and alg $U \mathrm{P}_{3}$ under the conditions used (Fig. 4, lanes 3, 6, and 9). Collectively, these findings support the model in which mucoidy and increased $\mathrm{rpoH}$ expression are co-ordinated in $P$. aeruginosa.

\section{Plasmid-borne wild-type mucA suppresses AlgU- dependent transcription from $\mathrm{rpoH} P_{3}$}

In order to confirm that the observed increase in $r p o H \mathrm{P}_{3}$ transcription in PAO578I (mucA22) was due to the lack of MucA, a wild-type mucA was introduced into this strain. In addition to the laboratory strain PAO578I, a previously characterized CF isolate carrying a sequenced mucA22 (CF23) (Martin et al., 1993c) was also tested. As previously described, introduction of the ptac-mucA $A^{+}$plasmid into these mucoid strains resulted in a non-mucoid phenotype (Martin et al., 1993c). RNA was isolated from PAO578I harbouring ptac-mucA $A^{+}$and CF23 containing ptac-mucA ${ }^{+}$ and subjected to $\mathrm{S} 1$ nuclease protection analysis. Examination of the $\mathrm{P}_{3}$ promoter of $\mathrm{rpoH}$ in the complemented strains showed that its AlgU-dependent transcription was suppressed when a functional mucA was present in trans (Fig. 5, lanes 2 and 4). Interestingly, the presence of extra copies of mucA suppressed $\mathrm{rpoH}$ transcription below the levels seen in wild-type $P$. aeruginosa (Fig. 5, lane 2 compared to Fig. 2A, lane 1). These results are consistent with the model in which MucA inhibits AlgU and prohibits initiation of transcription from the $\mathrm{P}_{3}$ promoter of $r p o H$. Collectively, these findings support the notion that mucA mutations, in addition to being an important mechanism responsible for conversion to mucoidy in $P$. aeruginosa, also increase expression of the gene encoding the major heat-shock sigma factor in this organism.

\section{Discussion}

In this study, we have mapped the 5' mRNA ends of the $P$. aeruginosa $\mathrm{rpoH}$ gene and found that there are three promoters located at positions $-25\left(\mathrm{P}_{1}\right),-36\left(\mathrm{P}_{2}\right)$ and $-41\left(P_{3}\right)$ relative to the start codon. The conclusion that $P$. aeruginosa $\mathrm{rpoH}$ contains an $\mathrm{AlgU}$-dependent promoter $\left(\mathrm{P}_{3}\right)$ is supported by the following experimental 


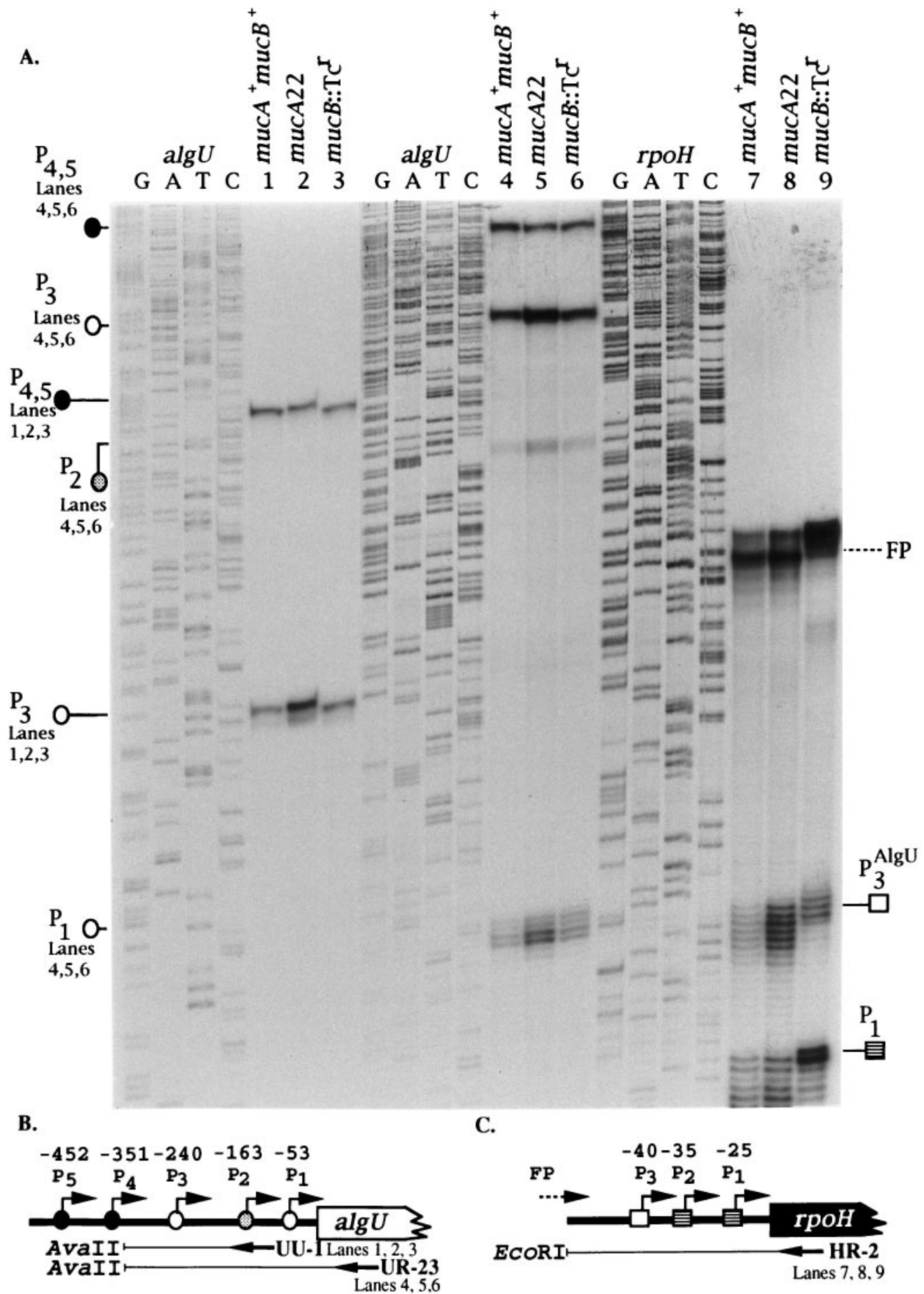

Fig. 4. Induction of AlgU-dependent transcription of algU and $r p o H$ in mucA mutants.

A. S1 nuclease protection analysis. Lanes: 1, PAO381 $\left(m_{u c A^{+}} \operatorname{mucB}^{+}\right)$; 2, PAO578I (mucA22); 3, PAO6857 (mucB::Tc ${ }^{\mathrm{R}}$ ) using an algU probe generated with oligonucleotide UU-1; 4,5 and 6 , same as lanes 1,2 and 3 using an algU probe generated with oligonucleotide UR-23; 7, 8 and 9, same as lanes 1,2 and 3 using an rpoH probe generated with oligonucleotide HR-2.

$\mathrm{B}$ and C. Schematic representation of probes, oligonucleotides and restriction sites used in S1 nuclease protection analyses. Negative numbers show relative positions of promoters with respect to the initiation codons of $a l g U$ and $r p o H$. Circles represent alg $U$ promoters, boxes indicate $\mathrm{rpoH}$ promoters as in (A). Open boxes and circles represent AlgU-dependent promoters; filled or patterned boxes and circles indicate other promoters; FP, band of full protection. All algU promoters (P1-P5) shown here have been previously described (Schurr et al., 1995a). 
A.

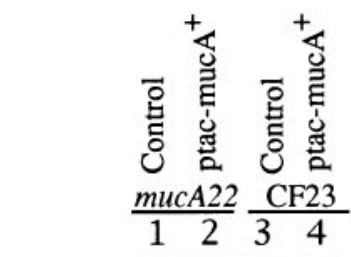

B.
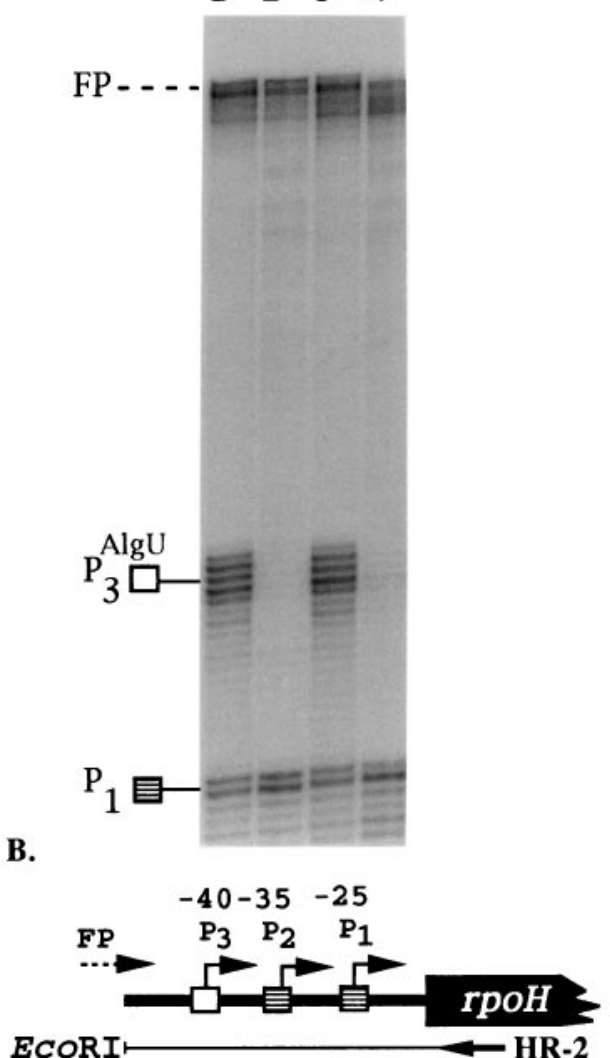

Fig. 5. Suppression of AlgU-dependent $r p o H$ transcription by mucA.

A. S1 nuclease protection analysis of RNA from mucoid strains PAO578I and CF23 with characterized mucA mutations (Martin et al., 1993c). Lanes: 1, PAO578I; 2, PAO578I harbouring ptac-mucA $A^{+} ; 3$, CF23; 4, CF23 harbouring ptac-mucA ${ }^{+}$. B. Schematic representation of probe, oligonucleotide (HR-2), and restriction sites used in $\mathrm{S} 1$ nuclease protection analysis. Boxes show same promoters as in Fig. 3; FP, band of full protection.

observations and additional considerations: (i) $\mathrm{P}_{3}$ transcription is absent in algU null mutants of $P$. aeruginosa; (ii) $\mathrm{P}_{3}$ transcription is initiated in vitro by AlgU-RNA polymerase holoenzyme; (iii) $P_{3}$ is induced under conditions of extreme heat shock; (iv) $P_{3}$ expression is increased in mucA mutant strains; and (v) the -35 (GAACTT) and -10 (TCaGA) regions of $\mathrm{P}_{3}$ conform with the AlgU $\left(\sigma^{\mathrm{E}}\right)$ consensus promoter sequence. These findings are also consistent with the interpretation that conversion to mucoidy and transcriptional activation of the heat-shock response in $P$. aeruginosa are co-ordinated and probably occur simultaneously in mucA mutants. This is evidenced by: (i) increased rpoH $\mathrm{P}_{3}$ transcription in mucA mutant strains; and (ii) suppression of $r p o H \mathrm{P}_{3}$ transcription by plasmid-borne $\mathrm{mucA}^{+}$introduced into laboratory and CF mucA mutants. MucA has been demonstrated to negatively regulate AlgU (Fig. $6 \mathrm{~A}$ ) and recent findings support the hypothesis that it does so by binding to AlgU (Martin et al., 1993c; Schurr et al., 1994; 1996; Xie et al., 1996). Since MucA, as shown here, also controls expression of $\mathrm{rpoH}$ it will be of interest to examine, in future studies, the extent of the effects of mucA mutations on the expression of $r p o H$-dependent genes. Such analyses are expected to reveal additional details and uncover the full extent of overlaps between the conversion to mucoidy and heatshock response in $P$. aeruginosa. It is possible that selection of mucA mutants in $\mathrm{CF}$ reflects not only the advantages due to the alginate coating but may provide additional protection to the pathogen because of the co-induction of other stress-response systems.

Two of the three mapped $r p o H$ promoters $\left(P_{1}\right.$ and $\left.P_{2}\right)$ are initiated by $\sigma^{70}$ as shown in this study. A previous
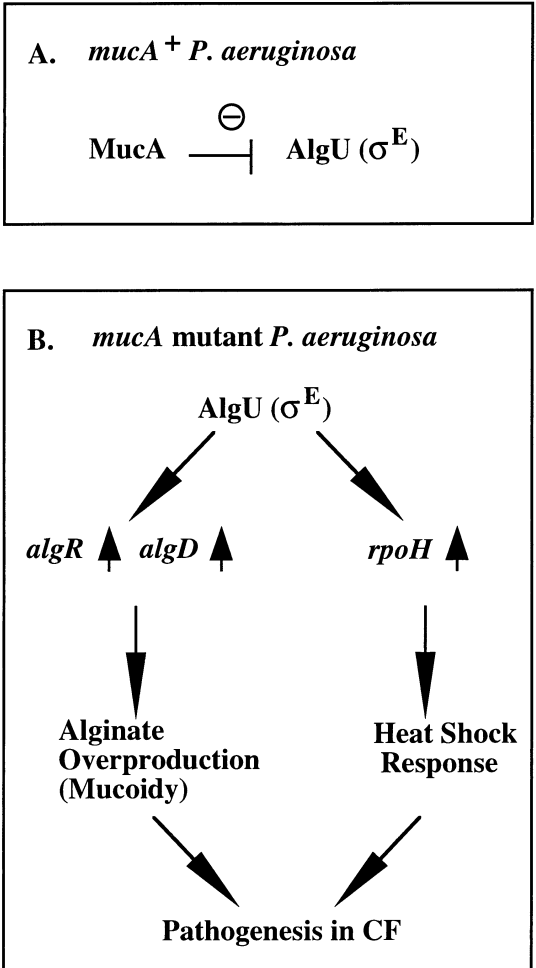

Fig. 6. Proposed model of co-induction of mucoidy and the heat-shock response in mucA mutants of $P$. aeruginosa. A. MucA is a negative regulator of AlgU. In cells with a functional mucA gene, AlgU activity is inhibited and colonies have non-mucoid morphology.

B. In strains carrying mucA mutations, AlgU activity is increased. This stimulates downstream events such as increased alginate production (conversion to mucoidy) and increased transcription of the heat-shock sigma-factor gene $r p o H$. This may cause induction of heat-shock response genes in $P$. aeruginosa, which encode highly conserved antigens as suggested by Jensen et al. (1993; 1995), that may contribute to the immunopathology in CF. 
report (Naczynski et al., 1995) examined transcription of $P$. aeruginosa $r p o H$ in the heterologous host $E$. coli. One of the mRNA $5^{\prime}$ ends observed in our study $\left(P_{1}\right.$ at -25$)$ matches with the initiation start sites reported by Naczynski et al. (1995). However, the $P_{3}$ transcriptional start site, mapped in our study in five strains to the same position $(-41)$, did not match any of the other bands reported by Naczynski et al. (1995) for plasmid-borne P. aeruginosa rpoH expressed in $E$. coli. A third band corresponding to full probe protection (Fig. 4A, lanes 7-9; FP) was also observed in our studies, suggesting the existence of at least one additional transcription initiation site. Such a transcript has not been reported by Naczynski et al. (1995). These and additional discrepancies are best explained by potential expression differences of the $P$. aeruginosa rpoH gene in $E$. coli and $P$. aeruginosa. The transcription from $\mathrm{P}_{2}$ observed in this study was detectable only on minimal media, which is reminiscent of medium-dependence for expression of one of the E. coli rpoH promoters (Nagai et al., 1990). It is also worth noting that it was difficult to detect $\mathrm{P}_{2}$ activity in vivo unless AlgU-dependent transcription from $\mathrm{P}_{3}$ was absent. At present, we do not know whether the physical proximity of the canonical -10 and -35 regions for the $P_{2}$ and the $P_{3}$ promoters or some other factors may be the basis for this apparent interference. However, as the two promoters are active under different physiological conditions, the occupancy of $P_{2}$ and $P_{3}$ may be mutually exclusive. Interestingly, the intensity of $P_{1}$ and $P_{2}$ transcripts in vitro (Fig. $3 B$ ) was in favour of $P_{2}$ in contrast to the relative intensity in vivo (Fig. 2B). However, the intensity of signals obtained in vitro may also reflect transcript size. It is also important to note that $P_{3}$ transcription was stronger than $P_{2}$ transcription under all conditions when both promoters were active.

Several studies have implicated stress proteins from different bacteria in the induction of autoimmune disease (Lamb et al., 1989; Oldstone, 1987; Young, 1990). Heatshock proteins of many pathogenic bacteria (e.g. Salmonella spp., E. coli, Chlamydia trachomatis, Mycobacterium spp., and Brucella spp.) are recognized by the immune system (Cameron et al., 1994; Cerrone et al., 1991; Elzer et al., 1994; Johnson et al., 1991; Roop et al., 1994; Tatum et al., 1994; van Eden et al., 1988) and have been implicated in bacterial virulence or in immunopathology associated with the sequelae of bacterial infections (Lamb et al., 1989; van Eden et al., 1988; Young, 1990). One of the recently studied proteins that belongs in this category is HtrA (DegP) (Lipinska et al., 1990; Strauch and Beckwith, 1988). HtrA is important for virulence of Salmonella (Johnson et al., 1991) and appears to play a role in the virulence of Brucella abortus (Elzer et al., 1996) and Yersinia enterolitica (Li et al., 1996). In P. aeruginosa, this factor has two homologues, algW and mucD (Boucher et al.,
1996). The mucD gene is believed to be under the control of AlgU. These relationships and the increased sensitivity to heat killing of algU mutants (Yu et al., 1995) have provided the basis for suggestions that the control of mucoidy and the heat-shock response may be intimately associated in $P$. aeruginosa. Such views are now corroborated in this study and extended to include the major heat-shock sigma-factor gene $r p o H$. Several general properties of the heat-shock response in $P$. aeruginosa have been investigated (Allan et al., 1988). It has been reported that 17 proteins with apparent molecular masses ranging from 15.7$103.4 \mathrm{kDa}$ are induced in response to temperature shifts from $37^{\circ} \mathrm{C}$ to $42^{\circ} \mathrm{C}$. It has also been shown that two of these proteins $(61 \mathrm{kDa}$ and $76 \mathrm{kDa})$ are immunologically similar to E. coli GroEL and DnaK, respectively (Allan et al., 1988). These studies have also confirmed that GroEL is one of the predominant proteins responding to heat shock in $P$. aeruginosa. GroEL ( $\mathrm{Hsp} \mathrm{60)}$ is a highly immunodominant molecule and is frequently recognized by antibodies in bacterial infections (Cerrone et al., 1991; van Eden et al., 1988). It is worth mentioning that a vigorous immune response to GroEL has been noted as a result of bacterial infections in CF (Jensen et al., 1993).

There are several lines of evidence indicating that an exuberant but apparently ineffective activation of the host immunological response contributes to the extensive tissue damage observed in chronic infections by $P$. aeruginosa in CF lungs (Boat et al., 1989). Furthermore, autoimmune pathology and rheumatoid abnormalities such as episodic or chronic erosive arthropathy, hypertrophic pulmonary osteoarthropathy, rheumatoid arthritis and diabetes mellitus have been associated with the chronic disease in CF (Coffey et al., 1989). While these processes are not understood at present, questions associated with these phenomena may be central to the issues of inflammation and associated morbidity and mortality in CF. It has been proposed that the highly conserved stress antigens of $P$. aeruginosa such as heat-shock proteins may play an important role in the immunopathology seen in CF (Jensen et al., 1995; Jensen et al., 1993). Thus it is possible that the putative induction of the heat-shock response, as a collateral effect of conversion to mucoidy (Fig. 6B) or as a part of selection for strains with upregulated stress systems during chronic colonization of the lung, may contribute to such processes in CF. Further in vitro and in vivo investigations of the rpoH-dependent regulon, which with a few exceptions (Fujita et al., 1993; Jensen et al., 1995) remains to be characterized in $P$. aeruginosa, and antigens whose production may be induced in mucA mutants may reveal important targets or modulators of the immune response in the context of the hypersensitivity reactions and inflammation leading to various manifestations of immune pathology in CF. 


\section{Experimental procedures}

\section{Bacterial strains, plasmids and growth conditions}

PAO1 is the standard genetic $P$. aeruginosa strain (Holloway, 1955). PAO6852 is an algU::Tc ${ }^{R}$ derivative of PAO1 described previously (Martin et al., 1994). PAO6857 is a $m u c B:: T^{R}$ derivative of PAO1 described previously (Schurr et al., 1996). CF23 and CF1 are mucA CF patient isolates that have been previously described (Martin et al., 1993c). ptac-mucA ${ }^{+}$is a pVDtac24 derivative carrying mucA under the control of the tac promoter as previously described (Martin et al., 1993c). pRK2013 is the plasmid that contains the tra functions used in triparental conjugations (Figurski and Helinski, 1979). pETU-1610 is the AlgU expression clone that produced the purified AlgU as previously described (Schurr et al., 1995b). $P$. aeruginosa was grown in Pseudomonas isolation agar (PIA) supplemented with $300 \mu \mathrm{g}$ of carbenicillin or $300 \mu \mathrm{g}$ of tetracycline when required. $E$. coli was grown in LuriaBertani (LB) medium supplemented with $25 \mu \mathrm{g} \mathrm{ml}^{-1}$ kanamycin, $30 \mu \mathrm{g} \mathrm{ml}^{-1}$ chloramphenicol and $40 \mu \mathrm{g} \mathrm{ml}^{-1}$ ampicillin as needed. Polymerase chain reaction (PCR) fragments were subcloned into the Invitrogen pCRII vector when cloned. $E$. coli BL21(DE3) pLysS (Studier and Moffat, 1986) was used for the overproduction and purification of AlgU.

\section{RNA isolation and S1 nuclease protection assay}

RNA was isolated as previously described (Schurr et al., 1995a). Uniformly labelled single-stranded probes were generated from M13 derivatives carrying the appropriate promoter region $(\mathrm{alg} U$ or $r p o H)$. The algU probe has been described previously (Martin et al., 1994; Schurr et al., 1995a). The $P$. aeruginosa $r p o H$ gene was cloned as a $967 \mathrm{bp} \mathrm{PCR}$ fragment using oligonucleotides HF-1 (5'-AGGCGGATCACGACCG-3', -109 to -94 relative to the start codon) and HR-1 (5'-CGATCAGCCGAGAATC-3', +941 to +958 relative to the ATG) and cloned into pCRII and termed pCRrpoH. The $\mathrm{rpoH}$ promoter region was subcloned from $\mathrm{pCRrpoH}$ into M13mp18 as an Xmnl/EcoRl 385 bp fragment. The oligonucleotide HR-2 (5'-CGAGTGCACGTAGGCTTCCA-3', +50 to +69 relative to the start codon) was used to generate a 188-nucleotide uniformly labelled $\alpha{ }^{-32} \mathrm{P}$ probe as previously described (Schurr et al., 1995a). This probe contained $10 \mathrm{bp}$ from the pCRII vector. The probe was hybridized to $50 \mu \mathrm{g}$ of RNA and treated with $\mathrm{S} 1$ nuclease as previously described (Martin et al., 1994).

\section{In vitro transcriptional run-off assay}

The in vitro run-off assay using AlgU with the $\mathrm{P}_{1}$ promoter of algU has been described previously (Schurr et al., 1995b). $\mathrm{His}_{10}$-AlgU was renatured by dilution (1:10) into renaturation buffer (total volume $30 \mu \mathrm{l}$ ) consisting of $100 \mathrm{mM}$ Tris- $\mathrm{HCl}$ (pH 7.5), 33\% glycerol, $10 \mathrm{mM} \mathrm{KCl}, 10 \mathrm{mM} \mathrm{MgCl}_{2}, 0.3 \mathrm{mM}$ ATP, $0.33 \mathrm{mg} \mathrm{ml}^{-1} \mathrm{GroEL}$ and $0.2 \mathrm{mg} \mathrm{m}^{-1}$ GroES (Epicentre Technologies) and incubated for $20 \mathrm{~min}$ at $25^{\circ} \mathrm{C}$. A standard sigma-factor/core RNA polymerase preincubation reaction $(6 \mu l)$ consisted of $3 \mu \mathrm{l}$ with $0.6 \mathrm{pmol}$ core RNA polymerase (Epicentre Technologies) freshly diluted in $10 \mathrm{mM}$ Tris- $\mathrm{HCl}$ (pH 8.0), $10 \mathrm{mM} \mathrm{KCl}, 10 \mathrm{mM} \beta$-mercaptoethanol, $1 \mathrm{mM}$ EDTA,
$0.4 \mathrm{mg} \mathrm{ml}^{-1}$ bovine serum albumin, $0.1 \%$ Triton $\mathrm{X}-100$ and $0.72 \mathrm{pmol} \mathrm{His}_{10}-\mathrm{AlgU}$ in $3 \mu \mathrm{l}$ of renaturation buffer. After $10 \mathrm{~min}$ on ice, DNA template $(0.1 \mathrm{pmol})$ was added to the RNA polymerase/sigma-factor mixture and incubated in transcription buffer $(40 \mathrm{mM}$ Tris- $\mathrm{HCl}, \mathrm{pH} 7.5,50 \mathrm{mM} \mathrm{KCl}, 5 \mathrm{mM}$ $\mathrm{MgCl}_{2}, 1 \mathrm{mM}$ DTT) for $10 \mathrm{~min}$ at $37^{\circ} \mathrm{C}$. Transcription was carried out in a final volume of $20 \mu \mathrm{l}$ and was initiated by addition of ATP, CTP and GTP $(200 \mu \mathrm{M}$ each), $20 \mu \mathrm{M}$ $\left[\alpha^{32} \mathrm{P}\right]-$ UTP $\left(8 \mathrm{Cimmol}^{-1}\right)$ to the DNA template/core RNA polymerase/sigma-factor mix and samples incubated for $15 \mathrm{~min}$ at $37^{\circ} \mathrm{C}$. The reaction was stopped and products separated on a sequencing gel. The rpoH $\mathrm{P}_{1-4} 47 \mathrm{bp}$ DNA template used in the in vitro run-off assay was generated by PCR using the oligonucleotides HF-1 and HR-3 (5'-GGAACCAAGGCATGTACAGG- $3^{\prime},+19$ to +38 relative to the rpoH start codon).

\section{AlgU purification}

AlgU was purified from E. coli BL21(DE3) pLysS (Studier and Moffat, 1986) using the expression vector pETU-1610 as previously described (Schurr et al., 1995b). E. coli BL21(DE3) pLysS cells containing pETU-1610 were grown in LB supplemented with $30 \mu \mathrm{g}$ of chloramphenicol and $40 \mu \mathrm{g}$ of ampicillin to an $\mathrm{OD}_{590}$ of 0.4 . AlgU production was induced by the addition of $1 \mathrm{mM}$ IPTG and incubated for $1 \mathrm{~h}$. The cells were collected and lysed in metal chelate affinity chromatography buffer containing $6 \mathrm{M}$ urea and $80 \mathrm{mM}$ imidiazole. The cellfree extract was chromatographed on an Ni-NTA agarose column washed with $100 \mathrm{mM}$ imidiazole. AlgU was eluted from the column by the addition of $200 \mathrm{mM}$ imidiazole. Fractions containing AlgU were pooled and AlgU was renatured prior to use as described above.

\section{Acknowledgements}

This study was supported by Grant Al31139 from the National Institute of Allergy and Infectious Diseases. M.J.S. was supported by Grant SCHURR95IO from the Cystic Fibrosis Foundation.

\section{References}

Allan, B., Linseman, M., MacDonald, L.A., Lam, J.S., and Kropinski, A.M. (1988) Heat shock of Pseudomonas aeruginosa. J Bacteriol 170: 3668-3674.

Benvenisti, L., Koby, S., Rutman, A., Giladi, H., Yura, T., and Oppenheim, A.B. (1995) Cloning and primary sequence of the $\mathrm{rpoH}$ gene from Pseudomonas aeruginosa. Gene 155: 73-76.

Boat, T.F., Welsh, M.J., and Beaudet, A.L. (1989) Cystic fibrosis. In The Metabolic Basis of Inherited Disease. Scriver, C.R., Beaudet, A.L., Sly, W.S., and Valle, D. (eds). New York: McGraw-Hill, pp. 2649-2680.

Boucher, J.C., Martinez-Salazar, J.M., Schurr, M.J., Mudd, M.H., Yu, H., and Deretic, V. (1996) Two distinct loci affecting conversion to mucoidy in Pseudomonas aeruginosa in cystic fibrosis encode homologues of the serine protease HtrA. J Bacteriol 178: 511-523.

Cameron, R.M., Stevenson, K., Inglis, N.F., Klausen, J., and Sharp, J.M. (1994) Identification and characterization of a 
putative serine protease expressed in vivo by Mycobacterium avium subsp. paratuberculosis. Microbiology 140: 1977-1994.

Cerrone, M.C., Ma, J.J., and Stephens, R.S. (1991) Cloning and sequence of the gene for heat shock protein 60 from Chlamydia trachomatis and immunological reactivity of the protein. Infect Immun 59: 79-90.

Coffey, M., Hassan, J., Feighery, C., Fitzgerald, M., and Bresnihan, B. (1989) Rheumatoid factors in cystic fibrosis: associations with disease manifestations and recurrent bacterial infections. Clin Exp Immunol 77: 52-57.

Deretic, V., Gill, J.F., and Chakrabarty, A.M. (1987) Gene $\operatorname{alg} D$ coding for GDPmannose dehydrogenase is transcriptionally activated in mucoid Pseudomonas aeruginosa. $J$ Bacteriol 169: 351-358.

Deretic, V., Schurr, M.J., Boucher, J.C., and Martin, D.W. (1994) Conversion of Pseudomonas aeruginosa to mucoidy in cystic fibrosis: environmental stress and regulation of bacterial virulence by alternative sigma factors. J Bacteriol 176: 2773-2780.

DeVries, C.A., and Ohman, D.E. (1994) Mucoid-to-nonmucoid conversion in alginate-producing Pseudomonas aeruginosa often results from spontaneous mutations in alg $T$, encoding a putative alternate sigma factor, and shows evidence for autoregulation. J Bacteriol 176: 66776687.

van Eden, W., Thole, J.E.R., van der Zee, R., Nordzij, A., van der Embden, J.D.A., Hensen, E.J., and Cohen, I.R. (1988) Cloning of the mycobacterial epitope recognized by $\mathrm{T}$ lymphocytes in adjuvant arthritis. Nature 331: 171-173.

Elzer, P.H., Phillips, R.W., Kovach, M.E., Peterson, K.M., and Roop, R.M.I. (1994) Characterization and genetic complementation of a Brucella abortus high-temperature-requirement A (htrA) deletion mutant. Infect Immun 62: 41354139.

Elzer, P.H., Phillips, R.W., Robertson, G.T., and Roop, R.M.I. (1996) The HtrA stress response protease contributes to resistance of Brucella abortus to killing by murine phagocytes. Infect Immun 64: 4838-4841.

Erickson, J.W., Vaughn, V., Walter, W.A., Neidhart, F.C., and Gross, C.A. (1987) Regulation of the promoters and transcripts of $r p o H$, the Escherichia coli heat shock regulatory gene. Genes Devel 1: 419-432.

Erickson, J.W., and Gross, C.A. (1989) Identification of the $\sigma^{\mathrm{E}}$ subunit of Escherichia coli RNA polymerase: a second alternate $\sigma$ factor involved in high-temperature gene expression. Genes Devel 3: 1462-1471.

Figurski, D.H., and Helinski, D.R. (1979) Replication of an origin-containing derivative of plasmid RK2 dependent on a plasmid function provided in trans. Proc Natl Acad Sci USA 76: 1648-1658.

Fujita, N., Nomura, T., and Ishihama, A. (1987) Promoter selectivity of Escherichia coli RNA polymerase: purification and properties of holoenzyme containing the heat-shock $\sigma$ subunit. J Biol Chem 262: 1855-1859.

Fujita, M., Tanaka, K., Takahashi, H., and Amemura, A. (1993) Organization and transcription of the principle $\sigma$ gene (rpoDA) of Pseudomonas aeruginosa PAO1: involvement of a $\sigma^{32}$-like RNA polymerase in rpoDA core expression. $J$ Bacteriol 175: 1069-1074.

Fyfe, J.A.M., and Govan, J.R.W. (1980) Alginate synthesis in mucoid Pseudomonas aeruginosa: a chromosomal locus involved in control. J Gen Microbiol 119: 443-450.

Goldberg, J.B., Gorman, W.L., Flynn, J., and Ohman, D.E. (1993) A mutation in algN permits trans activation of alginate production by alg $T$ in Pseudomonas species. $J$ Bacteriol 175: 1303-1308.

Govan, J.R.W., and Deretic, V. (1996) Microbial pathogenesis in cystic fibrosis: mucoid Pseudomonas aeruginosa and Burkholderia cepacia. Microbiol Rev 60: 539-574.

Grossman, A.D., Erickson, J.W., and Gross, C.A. (1984) The $h t p R$ gene product of $E$. coli is a sigma factor for heatshock promoters. Cell 38: 383-390.

Hershberger, C.D., Ye, R.W., Parsek, M.R., Xie, Z.-D., and Chakrabarty, A.M. (1995) The algT (algU) gene of Pseudomonas aeruginosa, a key regulator involved in alginate biosynthesis, encodes an alternative $\sigma$ factor $\left(\sigma^{\mathrm{E}}\right)$. Proc Natl Acad Sci USA 92: 7941-7945.

Hiratsu, K., Amemura, M., Nashimoto, H., Shinagawa, H., and Makino, K. (1995) The rpoE gene of Escherichia coli, which encodes $\sigma^{\mathrm{E}}$, is essential for bacterial growth at high temperature. J Bacteriol 177: 2918-2922.

Holloway, B.W. (1955) Genetic recombination in Pseudomonas aeruginosa. J Gen Microbiol 13: 572-581.

Jensen, P., Formsgaard, A., Shand, G., Hindersson, P., and Høiby, N. (1993) Antigenic analysis of Pseudomonas aeruginosa and Pseudomonas cepacia GroEL proteins and demonstration of a lipopolysaccharide-associated GroEL fraction in $P$. aeruginosa. APMIS 101: 621-630.

Jensen, P., Fomsgaard, A., Høiby, N., and Hindersson, P. (1995) Cloning and nucleotide sequence of the groE operon of Pseudomonas aeruginosa and Burkholderia cepacia. APMIS 103: 113-123.

Johnson, K., Charles, I., Dougan, G., Pickard, D., O'Gaora, P., Ali, T., Miller, I., and Hormaeche, C. (1991) The role of stress-response protein in Salmonella typhimurium virulence. Mol Microbiol 5: 401-407.

Lamb, J.R., Mendez-Samperio, P., Mehlert, A., So, A., Rothbard, J., Jindal, J., Young, R.A., and Young, D.B. (1989) Stress proteins may provide a link between the immune response to infection and autoimmunity. Int Immunol 1: 191-196.

Li, S., Dorrell, N., Everest, P.H., Dougan, G., and Wren, B.W. (1996) Construction and characterization of a Yersinia enterolitica 0:8 high-temperature requirement ( $h$ trA $)$ isogenic mutant. Infect Immun 64: 2088-2094.

Lipinska, B., Zylicz, M., and Georgopoulos, C. (1990) The HtrA (DegP) protein, essential for Escherichia coli survival at high temperature, is an endopeptidase. J Bacteriol 172: 1791-1797.

Lonetto, M.A., Brown, K.L., Rudd, K.E., and Buttner, M.J. (1994) Analysis of the Streptomyces coelicolor sigE gene reveals the existence of a subfamily of eubacterial RNA polymerase $\sigma$ factors involved in the regulation of extracytoplasmic functions. Proc Natl Acad Sci USA 86: 7573-7577.

Martin, D.W., Holloway, B.W., and Deretic, V. (1993a) Characterization of a locus determining the mucoid status of Pseudomonas aeruginosa: AlgU shows sequence similarities with a Bacillus sigma factor. J Bacteriol 175: 11531164.

Martin, D.W., Schurr, M.J., Mudd, M.H., and Deretic, V. 
(1993b) Differentiation of Pseudomonas aeruginosa into the alginate-producing form: inactivation of $m u c B$ causes conversion to mucoidy. Mol Microbiol 9: 497-506.

Martin, D.W., Schurr, M.J., Mudd, M.H., Govan, J.R.W., Holloway, B.W., and Deretic, V. (1993c) Mechanism of conversion to mucoidy in Pseudomonas aeruginosa infecting cystic fibrosis patients. Proc Natl Acad Sci USA 90: 83778381.

Martin, D.W., Schurr, M.J., Yu, H., and Deretic, V. (1994) Analysis of promoters controlled by the putative sigma factor AlgU regulating conversion to mucoidy in Pseudomonas aeruginosa: relationship to stress response. J Bacteriol 176: 6688-6696.

Naczynski, Z.M., Meuller, C., and Kropinski, A.M. (1995) Cloning the gene for the heat shock response positive regulator (sigma 32 homolog) from Pseudomonas aeruginosa. Can J Microbiol 41: 75-87.

Nagai, H., Yano, R., Erickson, J.W., and Yura, T. (1990) Transcriptional regulation of the heat shock regulatory gene rpoH in Escherichia coli: involvement of a novel catabolite-sensitive promoter. J Bacteriol 172: 2710-2715.

Oldstone, M.B. (1987) Molecular mimicry and autoimmune disease. Cell 50: 819-820.

Raina, S., Missiakas, D., and Georgopoulos, C. (1995) The $r p o E$ gene encoding the $\sigma^{\mathrm{E}}\left(\sigma^{24}\right)$ heat shock sigma factor of Escherichia coli. EMBO J 14: 1043-1055.

Roop, R.M.I., Fletcher, T.W., Sriranganathan, N.M., Boyle, S.M., and Schuring, G.G. (1994) Identification of an immunoreactive Brucella abortus HtrA stress response protein homolog. Infect Immun 62: 1000-1007.

Rouvière, P.E., De Las Penas, A., Mecsas, J., Lu, C.Z., Rudd, K.E., and Gross, C.A. (1995) rpoE, the gene encoding the second heat-shock sigma factor, $\sigma^{\mathrm{E}}$, in Escherichia coli. EMBO J 14: 1032-1042.

Roychoudhury, S., May, T.B., Gill, J.F., Singh, S.K., Feingold, D.S., and Chakrabarty, A.M. (1989) Purification and characterization of guanosine diphospho-D-mannose dehydrogenase. A key enzyme in the biosynthesis of alginate by Pseudomonas aeruginosa. J Biol Chem 264: 9380-9385.

Schurr, M.J., Martin, D.W., Mudd, M.H., Hibler, N.S., Boucher, J.C., and Deretic, V. (1993) The algD promoter: regulation of alginate production by Pseudomonas aeruginosa in cystic fibrosis. Cell Mol Biol Res 39: 371-376.

Schurr, M.J., Martin, D.W., Mudd, M.H., and Deretic, V. (1994) Gene cluster controlling conversion to alginate-overproducing phenotype in Pseudomonas aeruginosa: functional analysis in a heterologous host and role in the instability of mucoidy. J Bacteriol 176: 3375-3382.
Schurr, M.J., Yu, H., Boucher, J.C., Hibler, N.S., and Deretic, V. (1995a) Multiple promoters and induction by heat shock of the gene encoding the alternative sigma factor $\mathrm{AlgU}\left(\sigma^{\mathrm{E}}\right)$ which controls mucoidy in cystic fibrosis isolates of Pseudomonas aeruginosa. J Bacteriol 177: 5670-5679.

Schurr, M.J., Yu, H., Martinez-Salazar, J.M., Hibler, N.S., and Deretic, V. (1995b) Biochemical characterization and posttranslational modification of $\mathrm{AlgU}$, a regulator of stress response in Pseudomonas aeruginosa. Biochem Biophys Res Commun 216: 874-880.

Schurr, M.J., Yu, H., Martinez-Salazar, J.M., Boucher, J.C., and Deretic, V. (1996) Control of AlgU, member of the $\sigma^{\mathrm{E}}$-like family of stress sigma factors, by the negative regulators MucA and MucB and Pseudomonas aeruginosa conversion to mucoidy in cystic fibrosis. J Bacteriol 178: 4997-5004.

Strauch, K., and Beckwith, J. (1988) An Escherichia coli mutation preventing degradation of abnormal periplasmic proteins. Proc Natl Acad Sci 85: 1576-1580.

Studier, F.W., and Moffat, B.A. (1986) Use of bacteriophage T7 RNA polymerase to direct selective high-level expression of cloned genes. J Mol Biol 189: 113-130.

Tatum, F.M., Cheville, N.F., and Morfitt, D. (1994) Cloning, characterization and construction of $h t r A$ and $h t r A$-like mutants of Brucella abortus and their survival on BALB/c mice. Microb Pathogen 17: 23-26.

Wang, Q., and Kaguni, J.M. (1989) A novel sigma factor is involved in expression of the $\mathrm{rpoH}$ gene of Escherichia coli. J Bacteriol 171: 4248-4253.

Wozniak, D.J., and Ohman, D.E. (1994) Transcriptional analysis of the Pseudomonas aeruginosa genes algR, $\operatorname{alg} B$, and $\operatorname{alg} D$ reveals a hierarchy of alginate gene expression which is modulated by algT. J Bacteriol 176: 6007-6014.

Xie, Z.D., Hershberger, C.D., Shankar, S., Ye, R.W., and Chakrabarty, A.M. (1996) Sigma factor-anti-sigma factor interaction in alginate: inhibition of AlgT by MucA. J Bacteriol 178: 4990-4996.

Young, R.A. (1990) Stress proteins and immunology. Annu Rev Immun 8: 401.

Yu, H., Schurr, M.J., and Deretic, V. (1995) Functional equivalence of Escherichia coli $\sigma^{\mathrm{E}}$ and Pseudomonas aeruginosa AlgU: E. coli rpoE restores mucoidy and reduces sensitivity to reactive oxygen intermediates in algU mutants of $P$. aeruginosa. J Bacteriol 177: 3259-3268.

Yura, T., Nagai, H., and Mori, H. (1993) Regulation of the Heat-shock response in bacteria. Annu Rev Microbiol 47: 321-350. 